\title{
MUSEOS Y REDES SOCIALES, MÁS ALLÁ DE LA PROMOCIÓN
}

\author{
José Nicolás del Río Castro ${ }^{1}$ \\ Universidade de Santiago de Compostela \\ josenicolas.delrio@usc.es
}

Material original autorizado para su primera publicación en la revista académica REDMARKA. Revista Digital de Marketing Aplicado

https://doi.org/10.17979/redma.2011.03.07.4741

Recibido: 15 Noviembre 2011

Aceptado: 28 Noviembre 2011

\section{Resumen}

La popularidad de la Web 2.0, y en particular de las redes sociales, ha impulsado a los museos a estar presentes en espacios online como Facebook y Twitter, ajenos al ámbito museístico. El modelo de comunicación de este tipo de websites, basado en opiniones, comentarios y conversaciones escuetas, difiere sustancialmente del tipo de difusión que acostumbran a realizar los museos desde sus webs institucionales. Ajustar el discurso oficial del museo al formato que imponen las redes sociales no significa únicamente acomodar el mensaje escrito sino repensar su función. A partir de un seguimiento realizado a los 15 museos más visitados del mundo durante agosto, septiembre y octubre de 2011 en Facebook, se concluye que el uso de los medios sociales desaprovecha en gran medida la estrecha relación que se establece entre visitantes y museo, reduciendo el canal social a una herramienta básicamente autopromocional. Sin embargo, existen contados ejemplos de museos que, superando objetivos meramente publicitarios, muestran cómo una relación de proxi-

\footnotetext{
${ }^{1}$ Doctor en Arte por la Universidad de Santiago de Compostela, Master of Arts por la Universidad de Rutgers en EE.UU y estudios de Diseño Gráfico en la Escuela de Artes Visuales de Nueva York. A lo largo de su carrera ha compaginado su trabajo profesional como diseñador gráfico con labores docentes de posgrado en el Master de Creación y Comunicación Digital de la Universidade da Coruña y en el Master en Arte, Museología y Crítica Contemporáneas de la Universidad de Santiago de Compostela. También ha impartido cursos de grado y licenciatura en la facultad de Ciencias de la Comunicación de la Universidade da Coruña. Actualmente es investigador asociado de la Universidad de Santiago de Compostela.
} 
midad entre museo y público favorece la co-creación de proyectos museográficos.

Palabras clave: Web 2.0, redes sociales, museos

\section{Abstract}

The popularity of Web 2.0, and specifically of social networks, has driven museums to be present in websites such as Facebook and Twitter, which are foreign to the museum field. The communication model used by these types of websites, based on opinions, comments and terse conversations, differs substantially from the type of communication used by museums in their institutional websites. Adjusting the museum's discourse to the format imposed by social media doesn't mean to simply adjust the written message but to rethink its function. A follow-up of the activity in Facebook of the 15 most visited museums in the world during August, September, and October 2011, shows that social media do not seem to take advantage of a closer relationship between museums and their audiences. As a result, the social media's potential is generally downgraded to a self-promotional tool. However, there are some examples of museums which, having gone beyond promotional objectives, show how the proximity with the public encourages the co-creation of museographic projects.

Keywords: Web 2.0, social networks, museums 


\section{Introducción}

La popularidad de la Web 2.0, y en particular de las redes sociales, ${ }^{2}$ ha empujado a los museos a recurrir a espacios online de gran tráfico social, como Facebook y Twitter, en un esfuerzo por mantenerse al día. Hasta hace unos años, la comunicación museográfica en la Red tenía como único polo difusor la web oficial del museo pero con la llegada de la Web 2.0, el discurso oficial de la entidad se ha multiplicado (o disgregado, según el punto de vista) en webs externas al entorno institucional. Al participar en espacios creados por otros, los museos han tenido que ajustar sus contenidos a modelos de comunicación ajenos que, a priori, no resultan fáciles de acomodar a los cometidos de "estudio, educación y recreo" que figuran en la definición oficial de museo (ICOM 2007). ${ }^{3} \mathrm{~A}$ juzgar por las instituciones analizadas, el canal de comunicación que ofrecen las redes sociales apenas se utiliza para proyectos museográficos de sensibilización y educación. La presencia de los museos en las redes sociales se ha limitado a funcionar fundamentalmente como una herramienta promocional, cuyo objetivo último consiste en redirigir a los visitantes virtuales al museo físico.

Entonces, cabe preguntarse ¿son capaces los museos de usar las redes sociales más allá de una agenda constantemente actualizada y "canalizar la fuerza de la multitud"4 hacia la producción compartida de proyectos museográficos? La respuesta a esta cuestión depende, en gran medida, de la percepción que los propios museos tienen de la Web 2.0 y de lo que ella implica.

\footnotetext{
${ }^{2}$ En Inglaterra el uso de las redes sociales ha superado en popularidad a la industria del entretenimiento. Social networks beat entertainment sites as most popular UK online activity en The Telegraph, 16 de marzo de 2011. Disponible en: http://www.telegraph.co.uk/technology/news/ 8385859/Social-networks-beat-entertainment-sites-as-most-popular-UK-online-activity.html. Consultado el 8/09/2011.

${ }^{3}$ Según la última definición de museo aprobada por en Consejo Internacional de Museos en 2007 un museo es "una institución permanente, sin fines de lucro, al servicio de la sociedad y abierta al público, que adquiere, conserva, estudia, expone y difunde el patrimonio material e inmaterial de la humanidad con fines de estudio, educación y recreo."

Disponible en: http://icom.museum/quienes-somos/la-vision/definicion-del-museo/L/1.html Consultado el 18/09/2011

${ }^{4}$ Uno de los seis aspectos definitorios de la Web 2.0. (Anderson 2007: 14-26).
} 


\section{La Web 2.0 en museos}

La llegada de la Web 2.0 en $2005^{5}$ convirtió la Red en un espacio de creación, colaboración e intercambio. Los formatos $2.0^{6}$ se extendieron rápidamente; se trataba de tecnologías gratuitas y fáciles de utilizar que no requerían de intermediarios para publicar contenidos y llegar a una audiencia global. Su implantación en museos online contribuyó a modificar la experiencia de los visitantes, que ya no accedían sólo para leer información sino para "debatir, compartir y re-mezclar lo que consumían" (Simon, 2010). En otras palabras, la oferta de los museos en la Red dejó de ser únicamente de consulta y pasó a ser, también, de uso. Aplicadas al entorno de los museos, las tecnologías 2.0 sirvieron para que la participación de los visitantes se incorporase a tres espacios diferenciados. En primer lugar, dentro de la propia web del museo, principalmente a través de blogs $\mathrm{y}$, en menor medida, mediante foros y wikis. En segundo lugar, en repositorios externos donde compartir materiales audiovisuales: vídeos en You Tube, fotos en Flickr, audios en iTunes o presentaciones en SlideShare. Y, en tercer lugar, en las redes sociales, principalmente a través de Facebook y Twitter.

A pesar de gozar de una amplia implantación y de formar parte de las expectativas habituales de los usuarios de Internet, la adopción de formatos 2.0 por parte de los museos no es una decisión inocua. La apertura de espacios para la voz de los visitantes dentro del espacio institucional repercute en diferente grado en la comunicación institucional. Aunque las aportaciones de los visitantes suelen reducirse a pequeñas píldoras de opinión, para muchas instituciones representan una interferencia en el discurso experto del museo que, tradicionalmente, había dependido sólo de la institución. No resulta extraño, por tanto, que la implantación de la Web 2.0 en el ámbito museístico encuentre reticencias. Para algunas instituciones la comunicación del museo "se diluye deliberadamente con los aportes sustanciales de los usuarios" (MacArthur, 2007). Para

\footnotetext{
${ }^{5}$ Término acuñado por Tim O’Reilly, cuya definición original describía la Web 2.0 desde un punto de vista comercial y la identificaba como un conjunto de tecnologías que servían para detectar empresas innovadoras y hacer predicciones de mercados.

${ }^{6}$ A saber: blogs, wikis, etiquetas y marcadores sociales, repositorios para compartir archivos multimedia, podcasts, RSS y nuevos servicios 2.0 (redes sociales, mash-ups, etc.).
} 
otras, involucrarse en "espacios poco serios como Facebook" afecta a la percepción profesional del museo (Vogelsang y Zinder, 2011). Algunas temen, incluso, que la Web 2.0 pueda llegar a dejar obsoleta la institución física, al fomentar una imagen de "anticuados agrupadores de objetos fuera de línea" (Flatt 2010). A pesar de las dudas, no faltan visiones positivas, aunque conscientes de obstáculos internos: "adquirir mentalidad 2.0 (de conversar, compartir, colaborar y co-crear con los usuarios, de producir no ya para sino con los usuarios) requiere un cambio organizativo no exento [...] de algunas resistencias internas" (Rodá 2010:24). Will Gompertz, director de Tate Media, propone una visión optimista y vaticina que en el futuro los museos "dejarán de monopolizar el control de la información y [así] cada vez más gente participará en el desarrollo de contenidos compartidos" (El País, 2007). De hecho, el MoMa de Nueva York admite audioguías creadas por el público ${ }^{7}$ y otras instituciones de carácter cultural como la Enciclopedia Britannica, también reciben aportaciones externas (Wired 2008). En ambos casos, la aceptación final de las propuestas depende de una revisión previa del personal de la institución.

Las tecnologías 2.0 proporcionan al museo una serie de herramientas que validan la participación del público, integrándolo en el discurso del museo como crítico y colaborador. Pero el grado de implicación de la audiencia resulta difícil de valorar para los museos y puede provocar una actitud de recelo. En consecuencia, y dependiendo de la perspectiva de cada entidad, las iniciativas 2.0 pueden oscilar entre un uso informativo y promocional o un uso participativo y motivador. Los datos recogidos sobre la actividad en Facebook de los $15 \mathrm{mu}$ seos más visitados del mundo (The Art Newspaper 2011) ${ }^{8}$ durante los meses de agosto, septiembre y octubre de 2011, indican que el uso de las redes sociales está principalmente orientado a una labor publicitaria (ver Tabla 1).

Tabla 1. Seguimiento en Facebook de los 15 museos más visitados del mundo

\footnotetext{
${ }^{7}$ En 2004 el colectivo ArtMobs creó audio guías alternativas a las oficiales del MoMA de Nueva York. Su éxito en la Red hizo que el museo propusiese a los visitantes particulares crear las suyas y enviarlas. Esta propuesta aún sigue vigente. Véase: http://www.moma.org/visit/plan/ atthemuseum/createyourown

${ }^{8}$ Lista publicada en The Art Newspaper, oㅡ 223, abril 2011. Disponible en: http://www. theartnewspaper.com/attfig/attfig10.pdf. Consultado el 9/9/2011.
} 
(Datos de agosto, septiembre y octubre de 2011. Elaboración propia.)

$\mathrm{N}=$ Notificaciones $/ \mathrm{D}=$ Difusión de fondos $/ \mathrm{P}=$ Promociones $/ \mathrm{I}=$ Invitación a colaborar

AGO $\quad$ SEP $\quad$ OCT

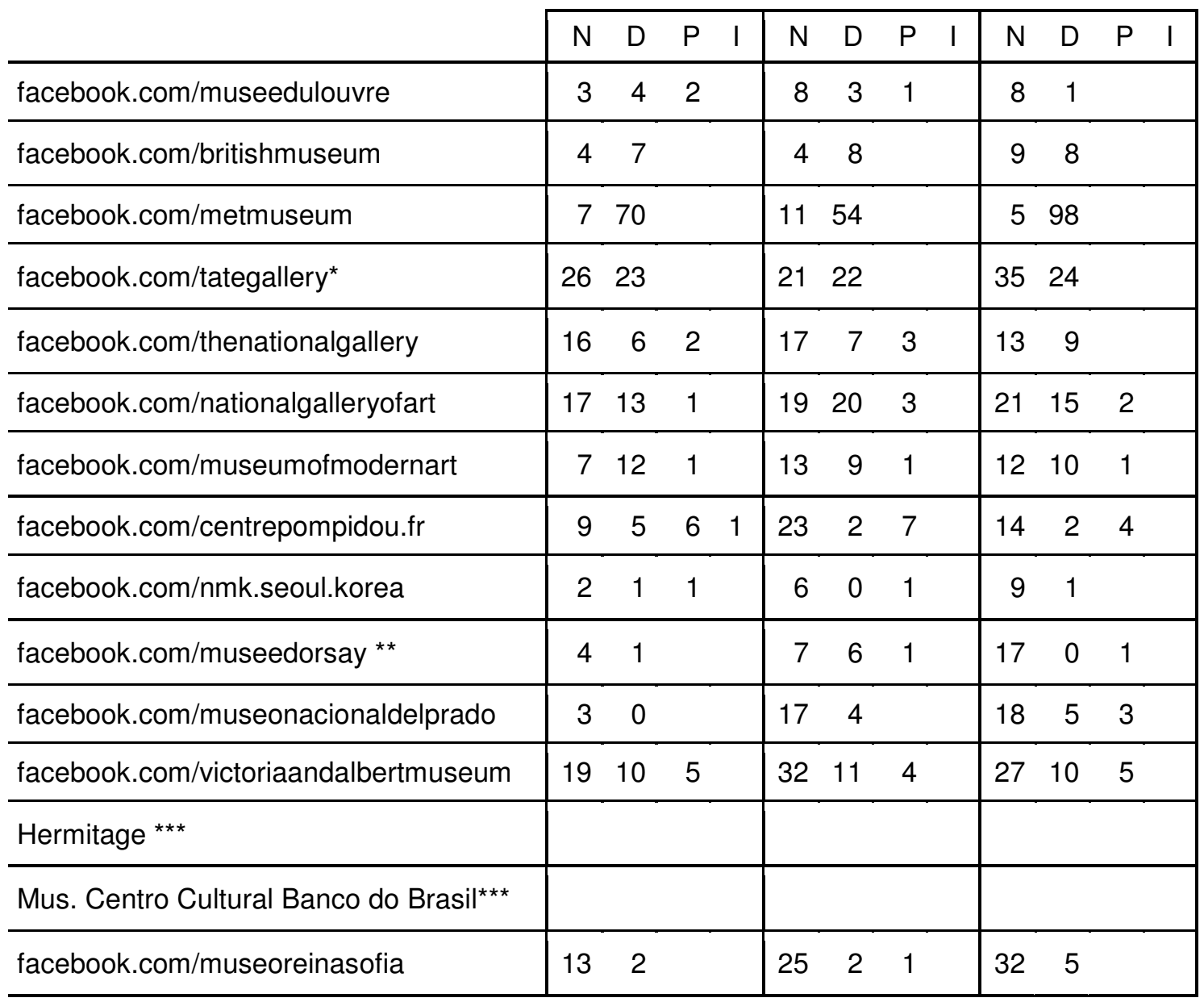

* Las cuatro galerías galerías de la Tate se engloban bajo una única cuenta.

** Estuvo cerrado por reformas hasta el 20 de octubre

*** Sin cuenta oficial en Facebook

\section{Los 15 museos más visitados del mundo. Seguimiento en Facebook}

Para el sondeo se establecieron cuatro categorías en función del tipo de comunicación: notificaciones (avisos y recordatorios de la programación del museo físico), promociones (concursos, productos de la tienda online, publicaciones, días de entrada gratuita, actualizaciones en la web, etc.), difusión (acercamiento a fondos artísticos y documentales mediante imágenes, textos, audios o vídeos) e invitaciones a colaborar en proyectos museográficos. 
Las cifras del sondeo proporcionan dos datos especialmente relevantes. El primero corresponde a la ausencia prácticamente total de proyectos museográficos en colaboración con el público. Sólo el Centro Pompidou se ha aproximado en cierto modo a proyectos de este tipo. El 22 de agosto el museo invitaba a las tres primeras personas que respondiesen a su notificación a visitar la exposición inaugural Brancusi, Images sans fin para comentarla a través de Twitter. Realmente, no se trata de un proyecto compartido con los visitantes ya que la exposición había sido previamente elaborada por el museo y a los seleccionados sólo se les ofrecía una visita especial. Un segundo aspecto de interés es que el número de notificaciones informativas sobre la programación del museo supera en prácticamente todos los casos al número de posts dedicados a la difusión de obras. La excepción es el Metropolitan de Nueva York y, parcialmente el British Museum, el Moma y la National Gallery of Art de Washington. Al sumar los totales vemos que de 1.296 notificaciones realizadas a través de Facebook durante tres meses, 717 (55,32\%) corresponden a avisos y recordatorios de la programación del museo físico, $523(40,35 \%)$ a contenidos divulgativos sobre fondos museográficos y documentales alojados en la web del museo y $56(4,32 \%)$ a acciones promocionales de diverso tipo.

\section{Las redes sociales como apoyo promocional}

Las redes sociales están basadas en el momento presente, en contenidos relacionados con la actualidad. Los museos se benefician de esa cercanía en el tiempo utilizando Facebook principalmente para promocionar las actividades en curso y de próxima inauguración en el museo físico. Sin embargo, los fondos de la colección son menos sensibles y menos dependientes de la contemporaneidad por lo que la difusión de fondos museográficos en las redes sociales menos frecuente y más difícil de encajar en un esquema temporal. $O$ bien se ofrecen aleatoriamente (Victoria \& Albert: " ¿Te has preguntado que ocurre de puertas adentro en restauración?”; Louvre: “¿Qué rey murió en el museo?”) o bien se busca una forma de acomodarlos a la misma estructuración cronológica $-y$ de caducidad- que siguen notificaciones y promociones. Para ello, algunos 
museos mantienen un pseudo-programa museográfico que presenta obras con cierta regularidad; por ejemplo, el Metropolitan propone la obra del día, la Tate la obra de la semana y la National Gallery de Londres la pintura del mes. Además de esta opción, cualquier otra excusa es válida para incluir referencias a los fondos del museo: efemérides (el Metropolitan recuerda: "hoy es el 130 aniversario del nacimiento de Picasso [...] ¿has visto...?"), celebraciones (el MOMA desea un feliz Halloween mostrando una calabaza sobre la que se proyecta "La noche estrellada" de Van Gogh) o incluso la meteorología (la Tate apuntalando un conocido tópico británico- escribe: "La previsión meteorológica de hoy recuerda al cuadro 'A Windy Day' de David Cox”). Independientemente de cómo se justifique la inclusión de posts divulgativos sobre la colección del museo, todos ellos funcionan como puntos de acceso a información adicional alojada en la web del museo. Desde este punto de vista los contenidos divulgativos funcionan como elementos promocionales, es decir, como señales o letreros que apuntan al lugar donde hay más información. Si las notificaciones en Facebook sirven para encaminar a los visitantes al museo físico, los posts divulgativos sirven para dirigir a los visitantes a la web del museo. En ambos casos el uso de las redes sociales es promocional.

Huelga decir que publicitar el museo para conseguir nuevos visitantes y consolidar los que ya lo han visitado es una labor legítima y necesaria. A este respecto, el apoyo que puedan brindar las redes sociales es, de por si, una razón suficiente para utilizarlas. No obstante, este esfuerzo, a pesar de utilizar un formato 2.0, parece contrario a su naturaleza. La información se transmite de forma unidireccional, de museo a visitantes, e ignora en gran medida el flujo contrario, que se reduce a concisas apreciaciones de los visitantes sobre la información presentada por el museo. Por tanto, la participación de los visitantes se reduce a comunicaciones a posteriori; a reacciones sobre propuestas previamente diseñadas al margen del público. Este tipo de propuestas desaprovechan la capacidad de participación y colaboración que caracteriza a los medios sociales. Los museos necesitan buscar planteamientos activos para las redes sociales y plantearse algo más que "simplemente hacer una página para sus seguidores 
en Facebook, escribir un blog o empezar a utilizar Twitter para ponerse al día con los cambios" (Sumo 2011).

Los museos son espacios ricos en contenidos y de gran interés para el público -así lo demuestran las cifras de visitantes (El País 2010) - ${ }^{9}$ pero su oferta online es principalmente estática e informativa. En este contexto, ¿qué papel pueden jugar las redes sociales más allá de la promoción? ¿Qué experiencias 2.0 se pueden plantear que impliquen a los visitantes en la producción de contenidos museográficos?

\section{Las redes sociales como germen de proyectos museográficos}

Los tres ejemplos siguientes recogen proyectos que usan el espíritu colaborativo de las redes sociales. En estas iniciativas, los museos "piden ayuda" a sus visitantes para crear exposiciones, para tomar decisiones curatoriales, o para seleccionar piezas artísticas. El resultado es que los participantes no sólo se sienten involucrados en un proyecto sino que su contribución es públicamente reconocida. Mediante estas experiencias los visitantes sienten que el museo les tiene en cuenta de una forma más valiosa que mediante avisos puntuales de la programación del museo.

\section{Click! - Brooklyn Museum ${ }^{10}$}

Se trata de una exposición fotográfica que invita a los visitantes presenciales, a la comunidad online y al público en general a participar en su creación. La inspiración para esta iniciativa procede del libro The Wisdom of Crowds (La sabiduría de la multitud) cuyo autor afirma que, a menudo, un grupo heterogéneo de personas toma decisiones más acertadas que un experto. La exposición Click! explora si esta afirmación puede aplicarse también a las artes visuales. El proceso se llevó a cabo en tres fases. En un primer momento se invitó a que los participantes enviasen una fotografía sobre el tema "las caras cambiantes de Brooklyn" junto con un texto de cada autor. Una vez finalizada esta fase, se

\footnotetext{
${ }^{9}$ En noviembre de 2010, durante el debate del estado de la cultura en España, la ministra confirmaba que "los museos estatales tienen hoy más visitantes virtuales que presenciales, y esas visitas virtuales se han incrementado un $23 \%$ respecto al año anterior".

${ }^{10} \mathrm{http}: / /$ www.brooklynmuseum.org/exhibitions/click
} 
abrió un foro online para que el público evaluase las imágenes, que estaban presentadas de forma anónima. Como parte de la evaluación, el público debía indicar su nivel de conocimientos sobre arte. Finalmente, la exposición se inauguró en el museo con una instalación organizada según el rango de popularidad alcanzado en la Red. Además, los visitantes también podían ver como habían sido evaluadas las obras por los grupos de público con diferentes conocimientos sobre arte. El resultado confirmó en un alto porcentaje la tesis del libro, ya que las imágenes más populares coincidían entre los diferentes sectores de público. Esta exposición no sólo permite al público opinar en redes sociales, blogs o foros, sino crear contenidos que llegan a integrarse en la oferta de exposiciones temporales del museo.

\section{Split Second - Brooklyn Museum ${ }^{11}$}

Al igual que en ejemplo anterior, la inspiración de este proyecto ("una fracción de segundo") procede de un libro. En este caso se trata de Blink: The Power of Thinking Without Thinking (Parpadear: la capacidad de pensar sin pensar). En esta iniciativa online y en la exposición resultante los visitantes ponen a prueba si la reacción inicial a una pieza artística se ve afectada por lo que sabemos, lo que nos preguntan o lo que nos dicen sobre ella. Esta actividad también está planteada en tres partes. En primer lugar se propone a los visitantes virtuales elegir entre dos dibujos en una breve fracción de tiempo. En segundo lugar, se pide a los participantes que expresen su opinión sobre la pieza elegida y que la sitúen en una escala. En la última fase se pide una valoración de una imagen acompañada de un típico texto interpretativo pero pudiendo consultar la imagen durante un tiempo ilimitado. Cada parte del ejercicio tiene como objetivo examinar cómo la información -o la falta de ella- puede afectar a la reacción que un visitante tiene de una obra artística. En resultado de esta experiencia fue una exposición inaugurada el 13 de julio de 2011. Los visitantes pudieron contemplar una selección de las obras que generaron mayor controversia durante el proceso de evaluación, junto con una visualización y análisis de los datos recogidos.

\footnotetext{
${ }^{11}$ http://www.brooklynmuseum.org/exhibitions/split_second/ 
Fill The Gap -- Luce Foundation Center, Smithsonian ${ }^{12}$

El Centro de la Fundación Luce, perteneciente al Museo de Arte Americano del Smithsonian, es un almacén de arte accesible al público que ocupa la tercera y cuarta planta del edifico del museo. ${ }^{13}$ Los fondos en almacén no son estáticos y con frecuencia salen para exposición o préstamo. Si una obra está en préstamo más de 12 meses, el equipo del museo busca otra obra para reemplazarla. Es un proceso más laborioso de lo que pudiera parecer puesto que es necesario trabajar con varios departamentos para asegurarse que la obra cabe en el espacio, que no tiene problemas de conservación, que es apropiado para el tema, y que no ha sido seleccionada para futuros préstamos o exposiciones. El museo decidió abrir al público la iniciativa Fill The Gap (Rellena el hueco) con la excusa de pedir ayuda a sus visitantes virtuales. Mediante una imagen publicada en Flickr ${ }^{14}$ se muestra información sobre las obras situadas alrededor del espacio y las medidas del hueco. Consultando la colección online del museo los visitantes pueden sugerir obras para rellenar el espacio vacío. Cuando una sugerencia es aprobada, se instala la obra y en la cartela se le da reconocimiento a la persona que la propuso. El proceso comenzó en febrero de 2009 y sigue hasta la actualidad; el último hueco a rellenar corresponde al 12 de agosto de $2011 .^{15}$

\section{Conclusiones}

Tradicionalmente los museos han medido su éxito en función del público que visitaba las salas. Posteriormente, la popularidad de los museos online hizo que las visitas virtuales también se incorporasen a las cifras globales de asistencia. Con la Web 2.0 ha aparecido un nuevo indicativo de usuarios: el número de visitantes suscritos a los canales del museo en las redes sociales. Sin embargo, el valor de los medios sociales no debiera juzgarse por el número de seguidores, sino por el grado de implicación de éstos en las producciones del museo. Desde este punto de vista, la comunicación social de los museos en la

\footnotetext{
12 http://eyelevel.si.edu/2009/03/in-this-case-fill-the-gap.html

13 http://americanart.si.edu/luce/about/

${ }^{14}$ http://www.flickr.com/photos/americanartmuseum/3253221929/

15 http://www.flickr.com/photos/americanartmuseum/sets/72157613328866883/
} 
Red resulta con frecuencia pobre, ya que tiende a funcionar principalmente como un vehículo promocional para captar y fidelizar visitantes presenciales. Aunque el objetivo de ampliar el número de visitantes es una actividad necesaria, utilizar las redes sociales únicamente con esta finalidad significa desaprovechar gran parte de su potencial social. Los pocos museos que han sacado partido a las redes sociales para co-crear y co-comisariar exposiciones han encontrado un público participativo que, muy posiblemente, volverá a visitar el museo para disfrutar de experiencias en las que es protagonista y no un mero espectador.

\section{Bibliografía}

ANDERSON, P. (2007). What is Web 2.0? Ideas, technologies and implications for education. JISC Technology and Standards Watch. Febrero 2007; pp. 14-26. Recuperado

el $7 / 10 / 2011$

de http://www.jisc.ac.uk/media/documents/techwatch/tsw0701b.pdf.

BESSER, H. (1997). The Transformation of the Museum and the Way it's Perceived. Recuperado el 12/10/2011 de http://besser.tsoa.nyu.edu/howard/Papers/garmil- transform.html.

EL PAíS (2007). Museos en el iPod. El País, 24 de diciembre de 2007. Recuperado el 4/9/2011 de http://www.elpais.com/ articulo/cultura/Museos/iPod/elpepucul/200712 24elpepicul_2/Tes

EL PAÍS (2010). 'Minidebate' en el Congreso sobre el estado de la Cultura. El País, 24 de noviembre de 2010. Recuperado el 17/10/2011 de http://www.elpais.com/ articulo/cultura/Minidebate/Congreso/estado/Cultura/elpepucul/20101124elpep ucul_4/Tes.

FLATT, Molly (2010). ¿Necesitan los museos a los medios de comunicación social, o más bien el boca a boca?. MUSE-A, Revista de los museos de Andalucía, Año 8, № 12 de mayo de 2010; pp 34-39.

MACARTHUR, M. (2007). Can museums Allow Online Users to Become Participants? Recuperado el 7/10/2011 de http://www.aam-us.org/pubs/ we- 
bexclusive/digitalmuseum.cfm

MARTY, P. (2004). The Evolving Roles of Information Professionals in Museums. Recuperado el 9/10/2011 de http://www.asis.org/Bulletin/Jun04/marty.htm

O'REILLY, T. (2005). What is Web 2.0?. Design Patterns and Business Models for the Next Generation of Software. Recuperado el 2/9/2011 de http://oreilly. com/web2/ archive/what-is-web-20.html

RODÁ, C. (2010). De 1.0 a 2.0: el viaje de los museos a la comunicación social". MUSE-A, Revista de los museos de Andalucía, Año 8, № 12, mayo de 2010; pp. 22-33.

SIMON, N. (2010). The Participarory Museum Santa Cruz, California: Museum 2.0

THE TELEGRAPH (2011). Social networks beat entertainment sites as most popular UK online activity. The Telegraph, 16 de marzo de 2011. Recuperado el 17/09/2011 de http://www. telegraph.co.uk/technology/news/ 8385859/ Social-networks-beat-entertainment -sites-as-most- popularUK-on line-activity.html.

VOGELSANG, A. y MINDER B. (2011). Audience+: A Holistic Approach to Developing Social Media Guidelines for Swiss Museums. Recuperado el 2/9/ 2011 de http://conference.archimuse.com/mw2011/papers/audience_a_ holistic_approach_to_developing_soc.

WIRED (2008). Encyclopaedia Britannica To Follow Modified Wikipedia Model. Wired, 9 de junio de 2008. Recuperado el 28/09/2011 de http://www.wired. com/epicenter/ 2008 /06/ency/

\section{Para citar este artículo}

del Río Castro, José Nicolás (15-12-2011). MUSEOS Y REDES SOCIALES, MÁS ALLÁ DE LA PROMOCIÓN.

REDMARKA - CIECID - Unidad de Investigación en Marketing Aplicado-Universidad de A Coruña Año IV, Número 7, V3, pp.111-123

ISSN 1852-2300

URL del Documento : cienciared.com.ar/ra/doc.php?n=1605

URL de la Revista : cienciared.com.ar/ra/revista.php?wid=39 